\title{
Specific Anion Effects on the Internal Structure of a poly( $N$-isopropylacrylamide) Brush
}

Timothy J. Murdoch, ${ }^{1}$ Ben A. Humphreys, ${ }^{1}$ Joshua D. Willott, ${ }^{1}$ Kasimir P. Gregory, ${ }^{1}$ Stuart W. Prescott, ${ }^{2}$ Andrew Nelson, ${ }^{3}$ Erica J. Wanless, ${ }^{1}$ Grant B. Webber ${ }^{1}$

${ }^{1}$ Priority Research Centre for Advanced Particle Processing and Transport, University of Newcastle, Callaghan, NSW 2308, Australia

${ }^{2}$ School of Chemical Engineering, UNSW Australia, UNSW Sydney, NSW 2052, Australia

${ }^{3}$ Australian Nuclear Science and Technology Organisation, Lucas Heights, NSW 2234, Australia

* corresponding author: Grant B. Webber, email: grant.webber@newcastle.edu.au, phone: +612 40339067 


\section{Coarse-graining sensitivity analysis}

Discretization of analytical forms for the volume fraction and corresponding scattering length density (SLD) profiles can lead to artefacts in the calculated reflectivity. The $Q$ range over which these artefacts are present is proportional to the reciprocal thickness of the layer, i.e. thicker layers lead to artefacts at lower $Q$ values. Therefore layers must be thin enough to avoid artefacts in the measured $Q$ range. To confirm that 50 layers was sufficient to avoid artefacts, the fractional change in calculated reflectivity relative to 50 layers as a function of the number of layers was calculated for the solution condition that exhibited the thickest tail region $\left(20^{\circ} \mathrm{C}\right.$ in $\left.100 \mathrm{mM} \mathrm{KSCN}\right)$ and is presented in Figure S1. The fractional change is large for small numbers of layers and decreases with increasing number of layers up to 50 (23.7 ̊̊ per layer). Increasing the number of layers to 1000 (1.2 $\AA$ per layer) has a maximum difference in reflectivity of $0.4 \%$ at $Q \sim 0.27 \AA^{-1}$ which is within the uncertainty of the measured reflectivity around this $Q$ value. For $Q$ values between $0.23 \AA^{-1}$ and 0.27 $\AA^{-1}$ the difference is less than $0.1 \%$, dropping to less than $0.03 \%$ for $Q$ values below $0.21 \AA^{-1}$. Thus 50 layers is judged to be sufficiently fine-grained for the thickest fitted tail and is therefore sufficient for all reported conditions.

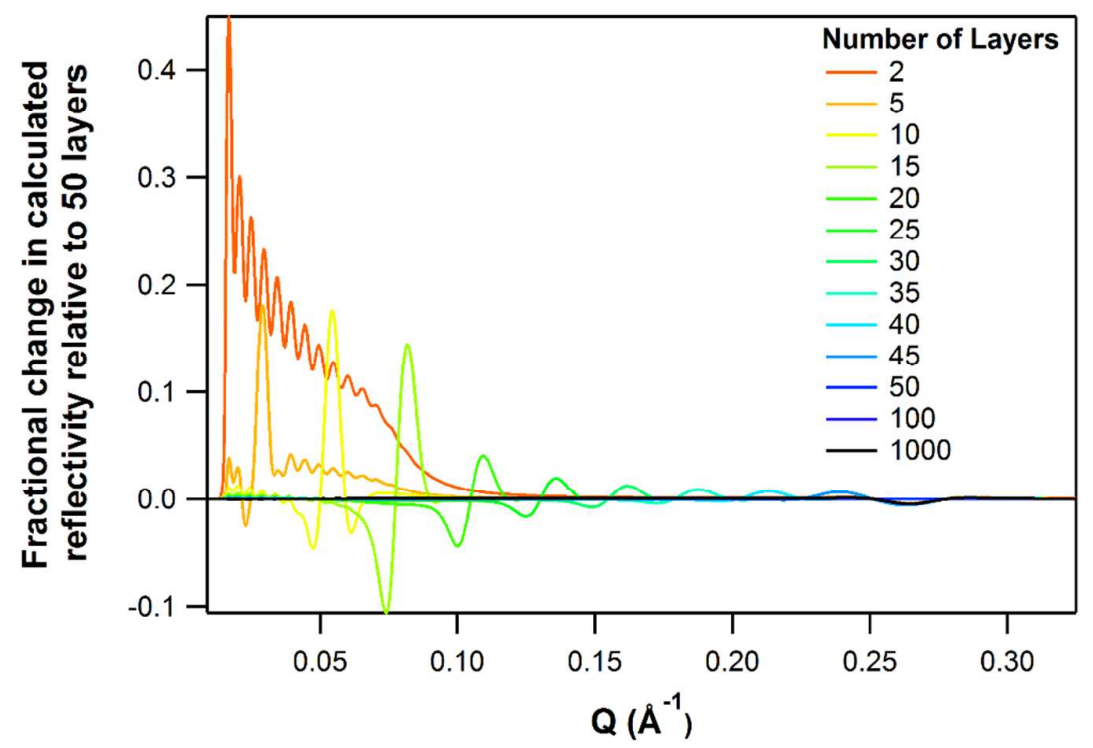

Figure S1. Fractional change in the calculated reflectivity relative to 50 layers for 2 up to 1000 layers. Data corresponds to the condition with the longest fitted tail region (100 mM potassium thiocyanate at $\left.20^{\circ} \mathrm{C}\right)$. 


\section{Approach to data fitting}

There are several possible approaches to fitting neutron reflectivity data for polymer brushes, of which slab based models are perhaps the most common. ${ }^{1-15}$ These models allow the determination of the density profile of the brush with no a priori assumptions regarding its shape. Another potential approach is to generate the volume fraction profile using a functional form (e.g. parabola with power law) that is informed by theories, such as self-consistent field theories (SCFT) of brushes. ${ }^{3,16}$ Initially, fits were attempted using hyperbolic tangent, Gaussian and parabola with a power law functional forms and are given in Figures $\mathrm{S} 2, \mathrm{~S} 3$ and $\mathrm{S} 4$ for the PNIPAM brush in $\mathrm{D}_{2} \mathrm{O}$ at $45,32.5$ and $20^{\circ} \mathrm{C}$. In all cases, a single functional form for the brush cannot reproduce the reflectivity data. The approach presented in the current work uses a combination of interior slab layers followed by a functional form for the tail. This approach has been used previously by Dunlop et al. to capture non-ideal structures near the substrate, e.g. high density surface layers, that are not accounted for in most polymer brush theories while minimising the number of fitting parameters. ${ }^{17}$ It is evident in Figures S2-4 that this approach significantly enhances the agreement between calculated and measured reflectivity. Figure $\mathrm{S} 4$ also presents fits with a single interior layer for a fully swollen brush. These fits demonstrate that a thin interior layer can generate the long-range oscillation (minimum at $Q \sim 0.07 \AA$ ), but cannot account for oscillations at low $Q$. A more sophisticated approach would be to use SCFT to generate the profiles directly and would allow additional structural details to be elucidated. ${ }^{18}$ However, this approach would be difficult to implement given the lack of accurate phase data for PNIPAM in the presence of salts and variations in reports of physical parameters such as persistence length. ${ }^{19}$ 

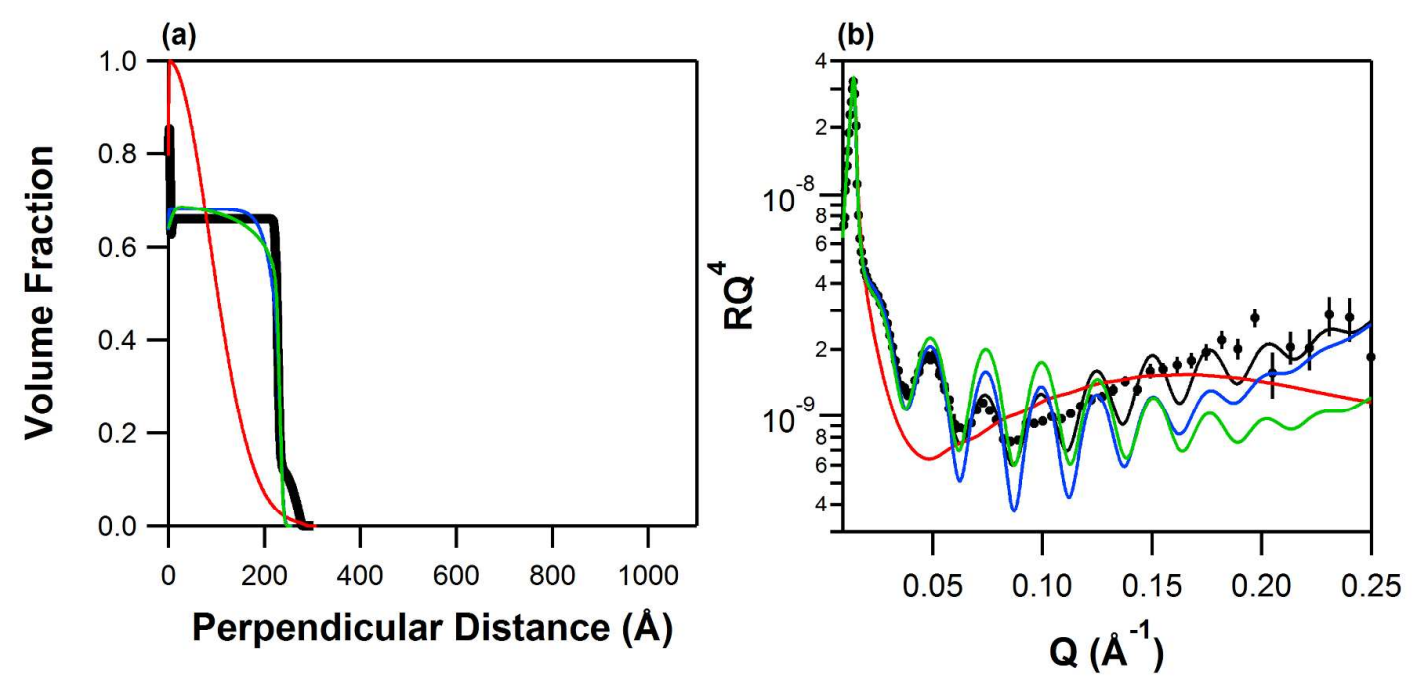

2 interior layers + Parabola with power law

Gaussian — Hyperbolic tangent — Parabola with power law

Figure S2. (a) Best fits for single functional forms for the brush volume fraction profile with (b) corresponding calculated reflectivity at $45^{\circ} \mathrm{C}$ in $\mathrm{D}_{2} \mathrm{O}$. Solid black lines correspond to the fits in the main manuscript while black markers show the measured reflectivity data

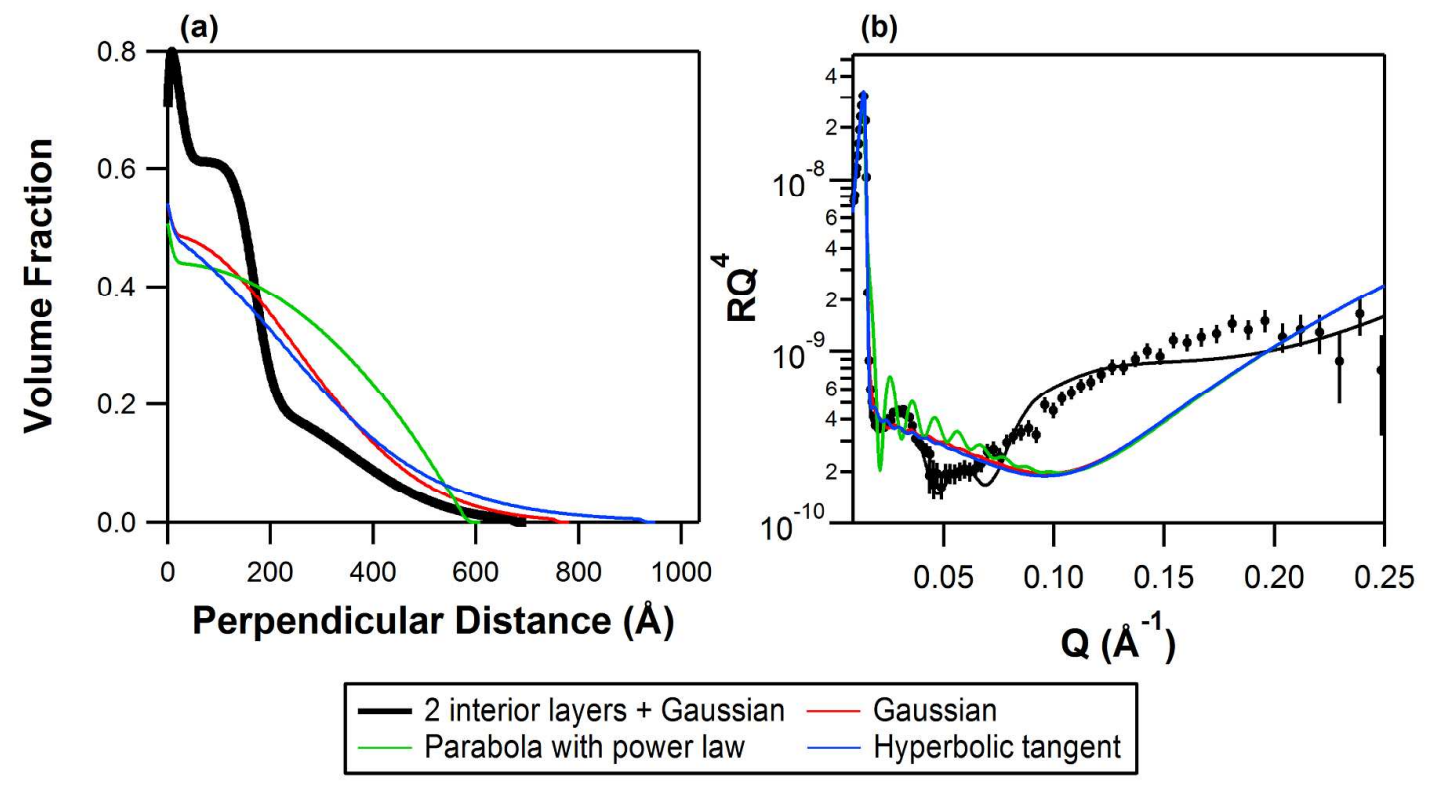

Figure S3. (a) Best fits for single functional forms for the brush volume fraction profile with (b) corresponding calculated reflectivity at $32.5^{\circ} \mathrm{C}$ in $\mathrm{D}_{2} \mathrm{O}$. Solid black lines correspond to the fits in the main manuscript while black markers show the measured reflectivity data 
(a)

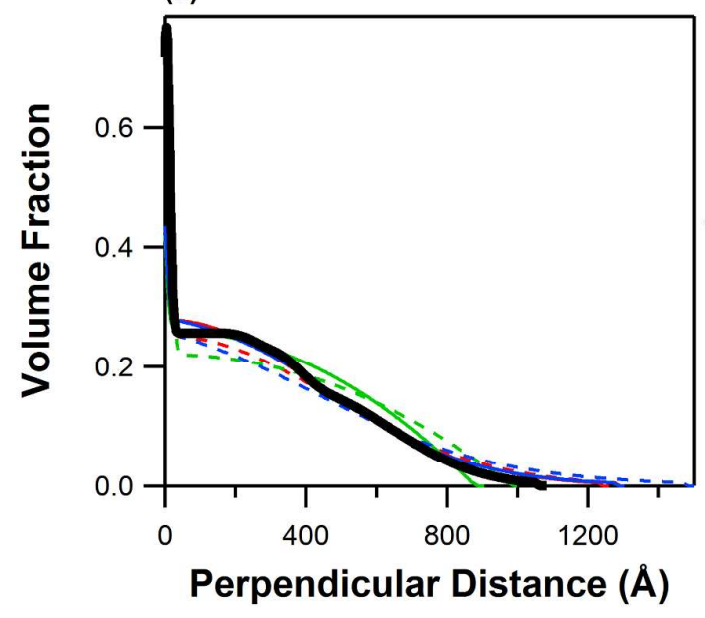

(b)

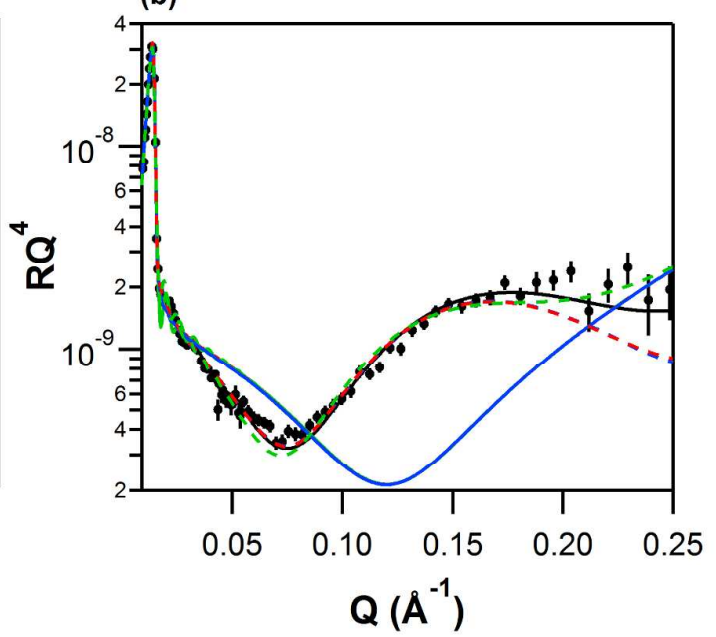

\begin{tabular}{|l|}
\hline-3 interior layers + Gaussian - Gaussian \\
- Parabola with power law \\
-1 interior layer + Gaussian
\end{tabular}

Figure S4: (a) Best fits for single functional forms for the brush volume fraction profile with (b) corresponding calculated reflectivity at $20^{\circ} \mathrm{C}$ in $\mathrm{D}_{2} \mathrm{O}$. Solid black lines correspond to the fits in the main manuscript while black markers show the measured reflectivity data. Dotted lines correspond to best fits for 1 interior layer with a corresponding functional form for the tail region. 


\section{Tabulated NR fits}

Tables S1-5 present the parameters for the model volume fraction profiles at each condition. The silicon dioxide layer used for all fits was 19.1 Å with a $3 \AA$ roughness to the silicon substrate. Fitting of the reflectivity for the brush in air yielded an SLD of the silicon dioxide of $3.1 \times 10^{-6} \AA^{-2}$, indicative of a slightly porous native oxide layer.

Table S1. Tabulated data for $\mathrm{D}_{2} \mathrm{O}$ volume fraction profiles.

\begin{tabular}{|c|c|c|c|c|c|c|c|c|}
\hline Temp. $\left({ }^{\circ} \mathrm{C}\right)$ & 45 & 40 & 35 & 32.5 & 30 & 27.5 & 25 & 20 \\
\hline$x^{2}$ & 7 & 6 & 6 & 5 & 7 & 8 & 3 & 4 \\
\hline Number Interior Layers & 2 & 2 & 3 & 2 & 3 & 3 & 4 & 3 \\
\hline Int. Thick. $1(\hat{A})^{a}$ & 3.9 & 5.0 & 6.8 & 22.7 & 21.6 & 17.2 & 13.6 & 12.3 \\
\hline$\phi_{1}$ & 1.00 & 1.00 & 0.95 & 0.85 & 0.81 & 0.94 & 0.97 & 0.93 \\
\hline Rough. $1^{b}$ & 4.5 & 4.5 & 4.5 & 4.5 & 4.5 & 4.5 & 4.5 & 4.5 \\
\hline Int. Thick. 2 (A) & 224.1 & 224.9 & 228.3 & 146.8 & 29.0 & 180.3 & 273.5 & 240.5 \\
\hline$\phi_{2}$ & 0.66 & 0.64 & 0.62 & 0.61 & 0.67 & 0.37 & 0.35 & 0.26 \\
\hline Rough. $2^{c}$ & 1.0 & 1.0 & 14.3 & 15.0 & 1.1 & 11.9 & 8.9 & 7.9 \\
\hline Int. Thick. 3 (Å) & - & - & 16.4 & - & 155.4 & 113.7 & 139.0 & 128.7 \\
\hline$\phi_{3}$ & - & - & 0.21 & - & 0.34 & 0.32 & 0.21 & 0.23 \\
\hline Rough. 3 & - & - & 19.3 & - & 21.1 & 44.4 & 64.5 & 38.8 \\
\hline Int. Thick. 4 (Â) & - & - & - & - & - & - & 202.26 & - \\
\hline$\phi_{4}$ & - & - & - & - & - & - & 0.08 & - \\
\hline Rough. 4 & - & - & - & - & - & - & 69.1 & - \\
\hline Tail $^{d}$ & $\mathrm{P}$ & $\mathrm{P}$ & No tail & G & G & G & No tail & G \\
\hline$\phi_{0}$ & 0.13 & 0.15 & - & 0.19 & 0.23 & 0.18 & - & 0.16 \\
\hline Characteristic $H(\AA))^{e}$ & 50.0 & 50.3 & - & 264.5 & 323.2 & 224.3 & - & 363.1 \\
\hline$Z_{0}(\AA)$ or $\alpha^{f}$ & 1.00 & 0.68 & - & - & 0.58 & & - & \\
\hline Rough. Int.| Ext. $(\hat{A})^{g}$ & 4.0 & 5.0 & - & 30.2 & 48.7 & 50.0 & - & 48.7 \\
\hline Rough. Ext.|Solv. $(A))^{h}$ & 5.0 & 5.0 & 62.9 & 5.0 & 5.0 & 5.0 & 97.4 & 5.0 \\
\hline
\end{tabular}

${ }^{a}$ Interior layer thickness, ${ }^{b}$ Interior roughness with previous layer, ${ }^{c}$ Fits are largely insensitive to this parameter, ${ }^{d}$ Exterior tail ( $\mathrm{P}=$ parabola with power law, $\mathrm{G}=$ Gaussian, $\mathrm{HT}=$ hyperbolic tangent $),{ }^{e}$ characteristic height of tail, ${ }^{f} \mathrm{Z}_{0}$ for $\mathrm{HT}$ or $\alpha$ for $\mathrm{P}$,

${ }^{g}$ Roughness between interior and exterior, ${ }^{h}$ Roughness between exterior and solvent 
Table S2. Tabulated data for $100 \mathrm{mM}$ potassium acetate volume fraction profiles.

\begin{tabular}{|c|c|c|c|c|c|c|c|c|c|}
\hline Temp. $\left({ }^{\circ} \mathrm{C}\right)$ & 45 & 40 & 35 & 32.5 & 30 & 27.5 & 25 & 22.5 & 20 \\
\hline$x^{2}$ & 11 & 13 & 9 & 5 & 4 & 5 & 4 & 4 & 4 \\
\hline $\begin{array}{c}\text { Number Interior } \\
\text { Layers }\end{array}$ & 3 & 3 & 3 & 3 & 4 & 2 & 2 & 2 & 2 \\
\hline Int. Thick. $1(\AA \AA)^{a}$ & 21.1 & 16.3 & 8.1 & 14.3 & 19.2 & 21.3 & 13.1 & 14.8 & 15.4 \\
\hline$\phi_{1}$ & 0.78 & 0.80 & 1.00 & 0.91 & 0.90 & 0.90 & 0.96 & 0.86 & 0.81 \\
\hline Rough. $1^{b}$ & 4.5 & 4.5 & 4.5 & 4.5 & 4.5 & 4.5 & 4.5 & 4.5 & 4.5 \\
\hline Int. Thick. 2 (Å) & 7.0 & 16.7 & 218.3 & 234.9 & 159.6 & 82.7 & 52.6 & 31.3 & 23.7 \\
\hline$\phi_{2}$ & 0.46 & 0.57 & 0.62 & 0.60 & 0.47 & 0.50 & 0.56 & 0.54 & 0.43 \\
\hline Rough. $2^{c}$ & 1.1 & 3.9 & 1.2 & 4.9 & 10.1 & 14.4 & 10.5 & 6.7 & 4.4 \\
\hline Int. Thick. $3(\AA)$ & 195.3 & 200.7 & 28.6 & 1.0 & 187.9 & 161.6 & - & - & \\
\hline$\phi_{3}$ & 0.69 & 0.65 & 0.37 & 0.22 & 0.24 & 0.61 & - & - & \\
\hline Rough. 3 & 1.3 & 1.6 & 25.3 & 17.2 & 50.5 & 35.1 & - & - & \\
\hline Int. Thick. 4 (Â) & - & - & - & - & - & 88.1 & - & - & \\
\hline$\phi_{4}$ & - & - & - & - & - & 0.1 & - & - & \\
\hline Rough. 4 & - & - & - & - & - & 27.1 & - & - & \\
\hline Tail $^{d}$ & No tail & No tail & No tail & No tail & No tail & G & G & G & G \\
\hline$\phi_{0}$ & - & - & - & - & - & 0.31 & 0.32 & 0.31 & 0.28 \\
\hline Characteristic $H(\AA)^{e}$ & - & - & - & - & - & 337.3 & 393.3 & 457.7 & 519.3 \\
\hline$Z_{0}(\AA)$ or $\alpha^{f}$ & - & - & - & - & - & 0.6 & 0.8 & 0.8 & 0.8 \\
\hline Rough. Int. | Ext. (Â) & - & - & - & - & - & 49.7 & 19.6 & 21.0 & 34.0 \\
\hline $\begin{array}{l}\text { Rough. Ext. |Solv. } \\
(\AA \AA)^{h}\end{array}$ & 11.1 & 13.5 & 6.6 & 66.7 & 94.1 & 5.0 & 5.0 & 5.0 & 5.0 \\
\hline
\end{tabular}

${ }^{a}$ Interior layer thickness, ${ }^{b}$ Interior roughness with previous layer, ${ }^{c}$ Fits are largely insensitive to this parameter, ${ }^{d}$ Exterior tail ( $\mathrm{P}=$ parabola with power law, $\mathrm{G}=$ Gaussian, $\mathrm{HT}=$ hyperbolic tangent) ${ }^{e}$ characteristic height of tail, ${ }^{f} \mathrm{Z}_{0}$ for $\mathrm{HT}$ or $\alpha$ for $\mathrm{P}$, ${ }^{g}$ Roughness between interior and exterior, ${ }^{h}$ Roughness between exterior and solvent 
Table S3. Tabulated data for $250 \mathrm{mM}$ potassium acetate volume fraction profiles.

\begin{tabular}{|c|c|c|c|c|c|c|c|c|c|}
\hline Temp. $\left({ }^{\circ} \mathrm{C}\right)$ & 45 & 40 & 35 & 32.5 & 30 & 27.5 & 25 & 22.5 & 20 \\
\hline$x^{2}$ & 8.4 & 10 & 8 & 9 & 6.8 & 3 & 4 & 2.77 & 3.8 \\
\hline $\begin{array}{c}\text { Number } \\
\text { Interior Layers }\end{array}$ & 3 & 3 & 3 & 3 & 3 & 4 & 3 & 2 & 2 \\
\hline $\begin{array}{c}\text { Int. Thick. } 1 \\
(\AA ̊ 丿)\end{array}$ & 6.21 & 7.90 & 9.11 & 8.71 & 11.11 & 15.36 & 17.16 & 12.16 & 11.76 \\
\hline$\phi_{1}$ & 1.00 & 1.00 & 1.00 & 1.00 & 1.00 & 0.90 & 0.93 & 1.00 & 1.00 \\
\hline Rough. $1^{b}$ & 4.50 & 4.50 & 4.50 & 4.50 & 4.50 & 4.50 & 4.50 & 4.50 & 4.50 \\
\hline Int. Thick. $2(\AA)$ & 1.00 & 1.00 & 1.02 & 216.60 & 176.71 & 202.31 & 41.18 & 55.59 & 44.17 \\
\hline$\phi_{2}$ & 0.26 & 0.18 & 0.18 & 0.61 & 0.60 & 0.53 & 0.60 & 0.67 & 0.58 \\
\hline Rough. $2^{c}$ & 7.78 & 7.61 & 8.16 & 1.67 & 4.87 & 10.64 & 9.64 & 7.54 & 1.00 \\
\hline Int. Thick. $3(\AA)$ & 224.93 & 229.59 & 198.23 & 26.52 & 65.80 & 107.66 & 94.54 & 109.82 & 190.00 \\
\hline$\phi_{3}$ & 0.66 & 0.64 & 0.63 & 0.43 & 0.54 & 0.22 & 0.45 & 0.25 & 0.32 \\
\hline Rough. 3 & 17.52 & 15.28 & 15.43 & 17.96 & 16.82 & 20.37 & 11.81 & 71.87 & 22.27 \\
\hline Int. Thick. $4(\AA \AA)$ & - & - & - & - & - & 53.57 & - & - & \\
\hline$\phi_{4}$ & - & - & - & - & - & 0.15 & - & - & \\
\hline Rough. 4 & - & - & - & - & - & 14.76 & - & - & \\
\hline Tail $^{d}$ & Not tail & No Tail & No tail & No tail & No tail & No tail & G & G & G \\
\hline$\phi_{0}$ & - & - & - & - & - & - & - & 0.30 & 0.30 \\
\hline $\begin{array}{c}\text { Characteristic } \\
\qquad H(\AA ̊ 丿))^{e}\end{array}$ & - & - & - & - & - & - & - & 396.01 & 437.40 \\
\hline$Z_{0}(A)$ or $\alpha^{f}$ & - & - & - & - & - & - & - & - & \\
\hline $\begin{array}{c}\text { Rough. Int.| } \\
\text { Ext. }(\AA)^{g}\end{array}$ & 3.75 & 40.33 & 22.54 & 14.09 & 29.85 & 30.78 & 47.79 & 34.30 & 21.90 \\
\hline $\begin{array}{c}\text { Rough. } \\
\text { Ext.|Solv. }(\AA ̊))^{h}\end{array}$ & 9.51 & 10.75 & 5.00 & 7.07 & 17.24 & 93.70 & 5.00 & 5.00 & 5.00 \\
\hline
\end{tabular}

${ }^{a}$ Interior layer thickness, ${ }^{b}$ Interior roughness with previous layer, ${ }^{c}$ Fits are largely insensitive to this parameter, ${ }^{d}$ Exterior tail $\left(\mathrm{P}=\right.$ parabola with power law, $\mathrm{G}=$ Gaussian, $\mathrm{HT}=$ hyperbolic tangent) ${ }^{e}$ characteristic height of tail, ${ }^{f} \mathrm{Z}_{0}$ for $\mathrm{HT}$ or $\alpha$ for $\mathrm{P}$, ${ }^{g}$ Roughness between interior and exterior, ${ }^{h}$ Roughness between exterior and solvent 
Table S4. Tabulated data for $100 \mathrm{mM}$ potassium thiocyanate volume fraction profiles.

\begin{tabular}{|c|c|c|c|c|c|c|c|c|c|}
\hline Temp. $\left({ }^{\circ} \mathrm{C}\right)$ & 45 & 40 & 37.5 & 35 & 32.5 & 30 & 27.5 & 25 & 20 \\
\hline$x^{2}$ & 7.7 & 7.5 & 8.4 & 4.8 & 3.5 & 4 & 3.3 & 4.4 & 4.9 \\
\hline \multicolumn{10}{|l|}{ Number Interior } \\
\hline Layers & 3 & 2 & 2 & 2 & 3 & 2 & 2 & 2 & 2 \\
\hline Int. Thick. $1(A)^{a}$ & 4.5 & 5.9 & 16.4 & 26.7 & 16.2 & 15.3 & 14.7 & 11.8 & 13.0 \\
\hline$\phi_{1}$ & 1.00 & 0.99 & 0.86 & 0.89 & 1.00 & 1.00 & 1.00 & 1.00 & 0.83 \\
\hline Rough. $1^{b}$ & 4.5 & 4.5 & 4.5 & 4.5 & 4.5 & 4.5 & 4.5 & 4.5 & 4.5 \\
\hline Int. Thick. 2 (Å) & 215.9 & 216.9 & 234.7 & 221.8 & 174.8 & 52.9 & 53.6 & 45.0 & 1.0 \\
\hline$\phi_{2}$ & 0.65 & 0.63 & 0.58 & 0.54 & 0.52 & 0.56 & 0.56 & 0.47 & 0.44 \\
\hline Rough. $2^{c}$ & 1.0 & 1.0 & 1.4 & 14.9 & 9.3 & 8.6 & 5.2 & 5.6 & 1.0 \\
\hline Int. Thick. 3 (Å) & 37.2 & - & - & - & 29.0 & - & - & - & \\
\hline$\phi_{3}$ & 0.10 & - & - & - & 0.04 & - & - & - & \\
\hline \multicolumn{10}{|l|}{ Rough. 3} \\
\hline Tail $^{d}$ & No Tail & HT & HT & $P$ & G & G & G & G & G \\
\hline$\phi_{0}$ & - & 0.21 & 0.09 & 0.05 & 0.19 & 0.35 & 0.32 & 0.31 & 0.27 \\
\hline Characteristic $H(\hat{A})^{e}$ & - & 48.9 & 190.2 & 236.0 & 279.2 & 354.5 & 385.4 & 435.0 & 593.2 \\
\hline$Z_{0}(\AA)$ or $\alpha^{f}$ & - & 31.8 & 20.2 & 0.98 & - & - & - & - & \\
\hline Rough. Int.| Ext. $(\AA)$ & - & 3.3 & 17.6 & 49.3 & 39.7 & 42.5 & 21.6 & 13.6 & 34.8 \\
\hline \multicolumn{10}{|l|}{ Rough. Ext. |Solv. } \\
\hline$(\AA ̊ \cap)^{h}$ & 2.8 & 5.0 & 5.0 & 5.0 & 5.0 & 5.0 & 5.0 & 5.0 & 5.0 \\
\hline
\end{tabular}

${ }^{a}$ Interior layer thickness, ${ }^{b}$ Interior roughness with previous layer, ${ }^{c}$ Fits are largely insensitive to this parameter, ${ }^{d}$ Exterior tail ( $\mathrm{P}=$ parabola with power law, $\mathrm{G}=$ Gaussian, $\mathrm{HT}=$ hyperbolic tangent), ${ }^{e}$ characteristic height of tail, ${ }^{f} \mathrm{Z}_{0}$ for $\mathrm{HT}$ or $\alpha$ for $\mathrm{P}$, ${ }^{g}$ Roughness between interior and exterior, ${ }^{h}$ Roughness between exterior and solvent 
Table S5. Tabulated data for $250 \mathrm{mM}$ potassium thiocyanate volume fraction profiles.

\begin{tabular}{|c|c|c|c|c|c|c|c|c|}
\hline Temp. $\left({ }^{\circ} \mathrm{C}\right)$ & 45 & 40 & 37.5 & 35 & 32.5 & 30 & 25 & 20 \\
\hline$x^{2}$ & 8.75 & 9 & 5.3 & 2.8 & 6.6 & 4.8 & 5.7 & 7.4 \\
\hline Number Interior Layers & 3 & 4 & 2 & 2 & 3 & 2 & 2 & 2 \\
\hline Int. Thick. $1(\hat{A})^{a}$ & 5.7 & 14.2 & 23.1 & 22.3 & 15.8 & 16.1 & 13.0 & 11.5 \\
\hline$\phi_{1}$ & 1.00 & 0.92 & 0.77 & 0.89 & 1.00 & 1.00 & 0.93 & 0.97 \\
\hline Rough. $1^{b}$ & 4.5 & 4.5 & 4.5 & 4.5 & 4.5 & 4.5 & 4.5 & 4.5 \\
\hline Int. Thick. $2(A)$ & 220.4 & 212.5 & 225.6 & 121.7 & 136.4 & 49.9 & 1.2 & 1.1 \\
\hline$\phi_{2}$ & 0.63 & 0.59 & 0.56 & 0.52 & 0.50 & 0.50 & 0.56 & 0.49 \\
\hline Rough. $2^{c}$ & 1.0 & 5.6 & 1.0 & 14.5 & 10.0 & 10.6 & 2.1 & 4.8 \\
\hline Int. Thick. 3 (A) & 40.6 & 16.5 & - & - & 167.6 & - & - & - \\
\hline$\phi_{3}$ & 0.08 & 0.51 & - & - & 0.26 & - & - & - \\
\hline Rough. 3 & 6.0 & 43.8 & - & - & 73.9 & - & - & - \\
\hline Int. Thick. 4 (A) & - & 8.1 & - & - & - & - & - & - \\
\hline$\phi_{4}$ & - & 0.63 & - & - & - & - & - & - \\
\hline Rough. 4 & - & 16.7 & - & - & - & - & - & - \\
\hline Tail $^{d}$ & No tail & No tail & G & HT & G & G & G & G \\
\hline$\phi_{0}$ & - & - & 0.10 & 0.89 & 0.13 & 0.36 & 0.31 & 0.30 \\
\hline Characteristic $H(A)^{e}$ & - & - & 110.2 & 368.1 & 208.2 & 350.1 & 509.8 & 524.8 \\
\hline$Z_{0}(A)$ or $\alpha^{f}$ & - & - & - & 27.1 & - & - & - & - \\
\hline Rough. Int. | Ext. (Â) ${ }^{g}$ & - & - & 21.3 & 8.9 & 49.4 & 11.6 & 23.8 & 31.7 \\
\hline Rough. Ext.|Solv. $(\hat{A})^{h}$ & 0.2 & 16.5 & 5.0 & 5.0 & 5.0 & 5.0 & 5.0 & 5.0 \\
\hline
\end{tabular}

${ }^{a}$ Interior layer thickness, ${ }^{b}$ Interior roughness with previous layer, ${ }^{c}$ Fits are largely insensitive to this parameter, ${ }^{d}$ Exterior tail ( $\mathrm{P}=$ parabola with power law, $\mathrm{G}=$ Gaussian, $\mathrm{HT}=$ hyperbolic tangent),${ }^{e}$ characteristic height of tail, ${ }^{f} \mathrm{Z}_{0}$ for $\mathrm{HT}$ or $\alpha$ for $\mathrm{P}$, ${ }^{g}$ Roughness between interior and exterior, ${ }^{h}$ Roughness between exterior and solvent 


\section{Lagrange multiplier approach}

The monotonic decay of polymer volume fraction away from the grafting interface leads to a gradual increase in SLD as the volume fraction of solvent must increase. In the swollen state, this gradual increase in SLD is similar to a diffuse or rough interface and results in a sharp drop in reflectivity after the critical edge with a relatively featureless reflectivity profile. The reflectivity is primarily sensitive to the shape of brush profile leading to a large variation in fitted effective dry brush thickness, $\delta$, as the length of the brush changes. To ensure that the amount of polymer is physically reasonable, a Lagrange multiplier was introduced into the minimization function, MINF, during fitting:

$$
M I N F=\chi^{2}+\mathcal{L}\left(\delta-\delta_{\mathrm{dry}}\right)^{2}=\sum_{i}\left(\frac{R_{\mathrm{calc}}-R_{\mathrm{exp}}}{S D_{\mathrm{exp}}}\right)^{2}+\mathcal{L}\left(\delta-\delta_{\mathrm{dry}}\right)^{2}
$$

where $R$ and $S D$ are the reflectivity and uncertainty as a function of $Q$ respectively, and $\mathcal{L}$ is the Lagrange multiplier. Subscript "calc" refers to the simulated data, with "exp" referring to the experimentally determined values. The first term in Equation S1 represents the error in the calculated reflectivity, i.e. $\chi^{2}$, while the second term reflects the deviation from the known amount of polymer. $\mathcal{L}$ was chosen such that $\chi^{2}$ was dominant during early iterations of the fitting with the amount of polymer playing a more important role once an appropriate shape of the volume fraction profile was established. The value of $\mathcal{L}$ was sufficiently low such that there was negligible difference between values of $\chi^{2}$ with and without the addition of the Lagrange multiplier.

\section{Atomic Force Microscopy experimental details and average curves}

Single-molecule force spectroscopy measurements (SMFS) were performed using a silicon nitride cantilever with backside reflective gold coating (DNP-10, Bruker, USA). For the colloid probe studies a single, dry native silica microsphere (Bangs Laboratories Inc., USA, diameter $\sim 5 \mu \mathrm{m}$ ) was glued (using two-part epoxy resin) onto a tipless rectangular silicon nitride cantilever with an aluminium backside coating (HQ:NSC36/tipless/AI BS, Mikromasch, USA). The spring constant of the cantilevers used was measured using the built-in thermal noise method (an average of 5 discrete measurements). For the SMFS measurements the spring constant was $0.08 \mathrm{~N} \cdot \mathrm{m}^{-2}$ and for the colloid probe study the spring constant was $2.2 \mathrm{~N} \cdot \mathrm{m}^{-2}$ (measured before and after gluing of colloid probe). Prior to in situ measurements, the fluid cell, O-ring and cantilevers were cleaned via ethanol and water rinses. The cantilevers were then exposed to UV/O 3 (15 min for SMFS cantilever and $2 \mathrm{~min}$ for colloid probe cantilever). 
Average AFM approach curves in $\mathrm{H}_{2} \mathrm{O}, 250 \mathrm{mM}$ potassium acetate and $250 \mathrm{mM}$ potassium thiocyanate with corresponding data from the most representative curve are given in Figures S5, S6 and S7 respectively. The shaded region represents \pm 2 standard deviations about the average for the $37^{\circ} \mathrm{C}$ data in each condition. Note that these uncertainties are typical for all conditions. The spikes in the shaded region in Figure $\mathbf{S 6}$ result from variations in the separation at which the first attractive event occurs; no repulsive events were observed at this separation.

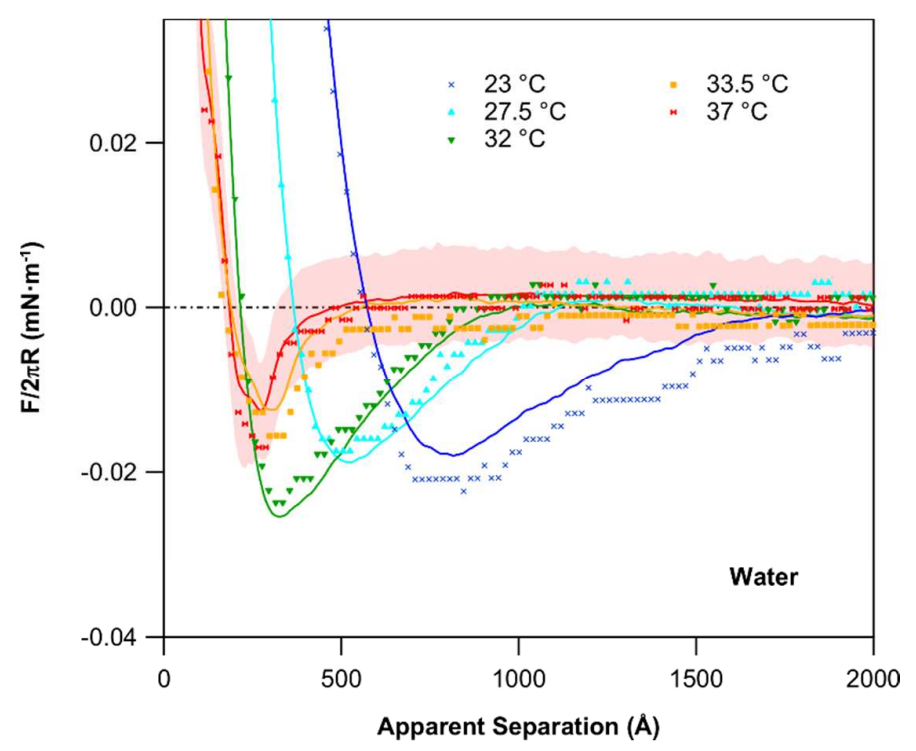

Figure S5. Average force versus apparent separation curves for the approach of a silica colloid toward a $183 \AA$ PNIPAM brush in water. Data points are from the experimental curve most representative of the average. The shaded region represents \pm 2 standard deviations from the average curve at $37^{\circ} \mathrm{C}$ 


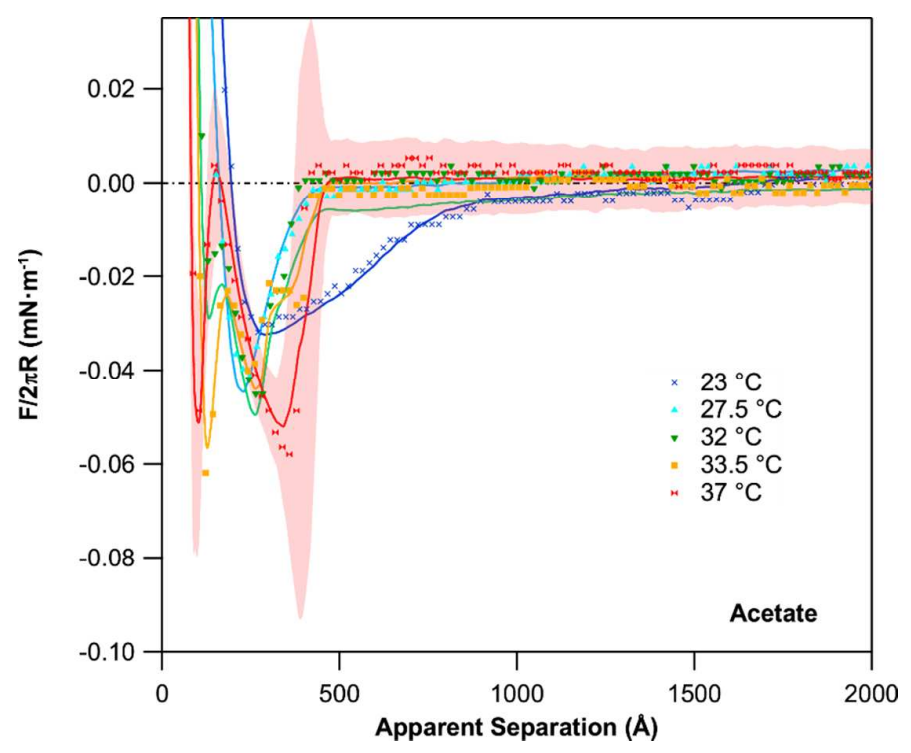

Figure S6. Average force versus apparent separation curves for the approach of a silica colloid toward a 183 A PNIPAM brush in $250 \mathrm{mM}$ potassium acetate. Data points are from the experimental curve most representative of the average. The shaded region represents \pm 2 standard deviations from the average curve at $37^{\circ} \mathrm{C}$

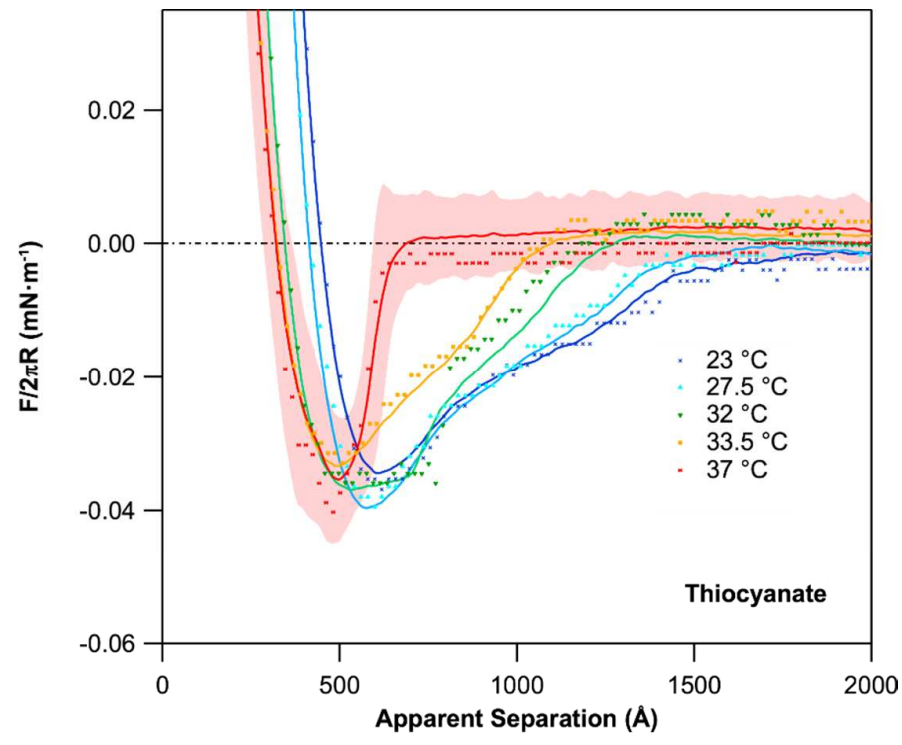

Figure S7. Average force versus apparent separation curves for the approach of a silica colloid toward a $183 \AA$ PNIPAM brush in 250 potassium thiocyanate. Data points are from the experimental curve most representative of the average. The shaded region represents \pm 2 standard deviations from the average curve at $37^{\circ} \mathrm{C}$ 
6. SMFS results

Table S6. SMFS results for PNIPAM brush in pure water at $22^{\circ} \mathrm{C}$.

\begin{tabular}{|c|c|c|c|c|}
\hline $\begin{array}{c}\text { Persistence } \\
\text { length }(\AA)\end{array}$ & $\begin{array}{c}\text { Contour length } \\
(\AA)\end{array}$ & $\begin{array}{c}\text { Molecular weight } \\
\left(\mathbf{k g} \cdot \mathrm{mol}^{-1}\right)\end{array}$ & $\begin{array}{c}\text { Grafting density } \\
\left(\AA^{-2}\right)\end{array}$ & $\begin{array}{c}\text { Reduced grafting } \\
\text { density }\end{array}$ \\
\hline $7.9 \pm 5.3$ & $4980 \pm 1180$ & $201 \pm 48$ & $0.0007 \pm 0.001$ & $40 \pm 14$ \\
\hline
\end{tabular}

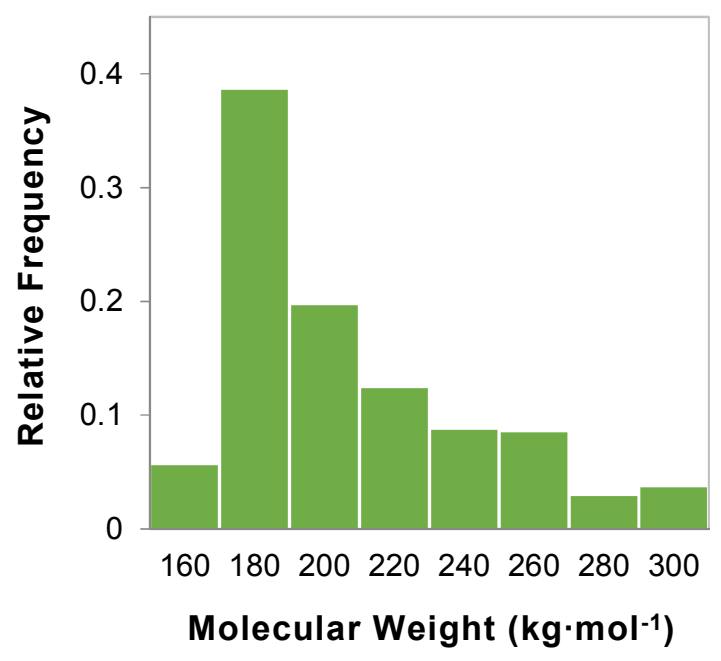

Figure S8. Molecular weight distribution histogram for PNIPAM brush. SMFS measurements performed in pure water at $22^{\circ} \mathrm{C}$. 


\section{Determination of polymer scattering length density (SLD) and adsorbed amount}

The dry brush thickness, $\delta_{\text {dry }}$ is required to evaluate whether the volume fraction profiles generated are physically reasonable. To determine $\delta_{\text {dry }}$ from the measurements in air the polymer SLD, $\rho_{\mathrm{N}, \mathrm{PNIPAM}}$, must be known. This is straightforward if the bulk density of the polymer is known. However, there is significant variation in reported bulk densities of PNIPAM that prevents confident determination of the polymer SLD (see main manuscript). An alternate approach relies on the fact that the fits of the brush in air and at $45^{\circ} \mathrm{C}$ are well approximated by a single slab of constant SLD with an unknown volume fraction, $\phi$, and a known length, $L$. Assuming that the fitted SLD at each condition is equal to the volume fraction weighted sum of the polymer and the solvent leads to:

$$
\begin{gathered}
\rho_{\mathrm{N}, \text { air }}=\rho_{\mathrm{N}, \text { PNIPAM }} \phi_{\text {ambient }}+\rho_{\mathrm{N}, \mathrm{H}_{2} \mathrm{O}}\left(1-\phi_{\text {ambient }}\right) \\
\rho_{\mathrm{N}, 45}=\rho_{\mathrm{N}, \text { PNIPAM }} \phi_{45}+\rho_{\mathrm{N}, \mathrm{D}_{2} \mathrm{O}}\left(1-\phi_{45}\right)
\end{gathered}
$$

where subscripts "ambient" and " 45 " refer to the measurements of the brush in air and the brush in $\mathrm{D}_{2} \mathrm{O}$ at $45^{\circ} \mathrm{C}$ respectively

To constrain the system we utilize the fact that the adsorbed amount must be the same for both conditions:

$$
\phi_{\text {ambient }} L_{\text {ambient }}=\phi_{45} L_{45}=\delta_{\text {dry }}
$$

Solving equations S2, S3 and S4 simultaneously yields the volume fraction at each condition, $\delta_{\mathrm{dry}}$ and $\rho_{\mathrm{N}, \mathrm{PNIPAM}}$. The fitting procedure was repeated multiple times for 3 slab, 2 slab and 1 slab fits with average input and output values shown in Table S7. Note that $\rho_{\mathrm{N}_{\mathrm{D}} \mathrm{O}} \mathrm{O}$ was not constrained during the fitting process to better capture data around the critical edge. A solvent SLD value of $6.15 \times 10^{-6} \AA^{-2}$ was found for $250 \mathrm{mM}$ potassium acetate due to the significant amount of hydrogenated acetic acid that was required to adjust the $\mathrm{pH}$ due in this self-buffering system.

Table S7. Average Input and Output Values for determination of SLD and adsorbed amount

\begin{tabular}{|c|c|c|c|}
\hline \multicolumn{2}{|c|}{ Inputs } & \multicolumn{2}{|c|}{ Outputs } \\
\hline$L_{\text {air }}(\AA)$ & $191 \pm 1$ & $\phi_{\text {air }}$ & $0.81 \pm 0.01$ \\
\hline$L_{45}(\AA)$ & $231 \pm 4$ & $\phi_{45}$ & $0.67 \pm 0.01$ \\
\hline$\rho_{\mathrm{N}, \text { ambient }}\left(\times 10^{-6} \AA^{-2}\right)$ & $0.635 \pm 0.02$ & $\delta_{\text {dry }}(\AA \hat{A})$ & 153 \\
\hdashline$\rho_{\mathrm{N}, 45}\left(\times 10^{-6} \AA^{-2}\right)$ & $2.68 \pm 0.04$ & $\rho_{\mathrm{N}, \mathrm{PNIPAM}}\left(\times 10^{-6} \AA^{-2}\right)$ & $0.93 \pm 0.01$ \\
\hline
\end{tabular}


8. Ellipsometry and QCM-D measurements in $\mathrm{H}_{2} \mathrm{O}$
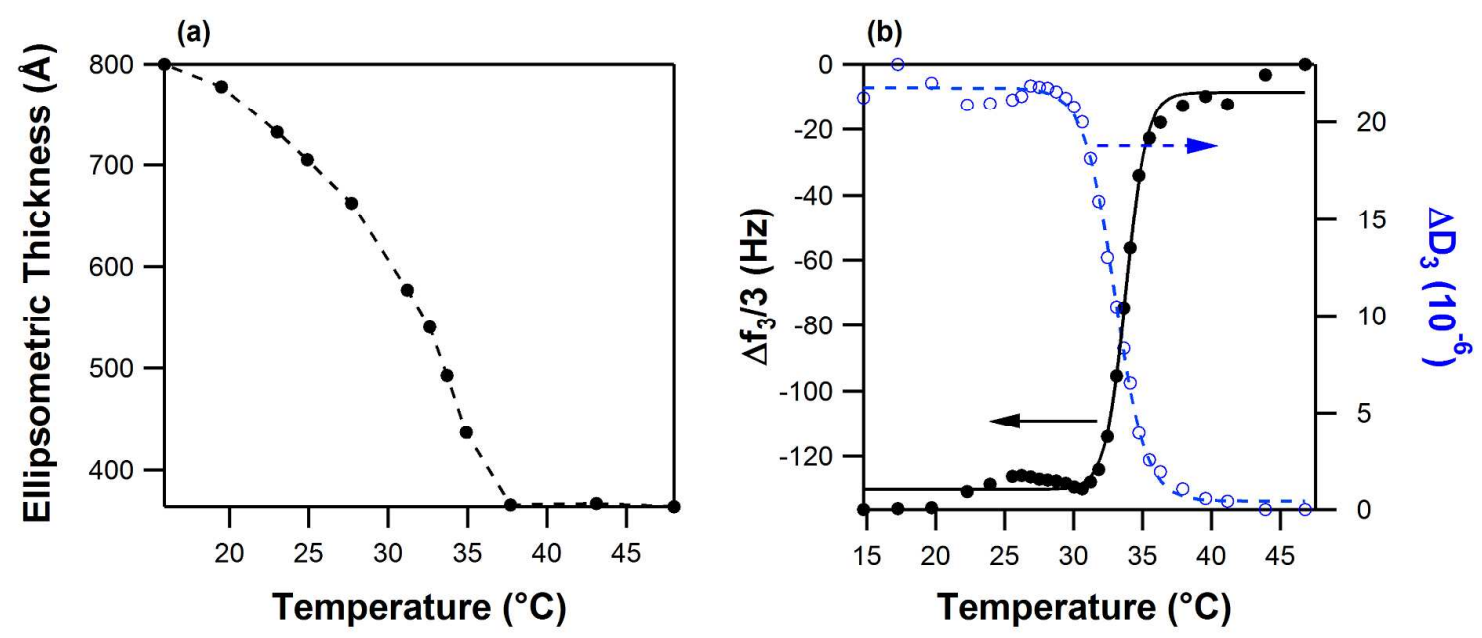

Figure S9. (a) Ellipsometric thickness of a $186 \pm 5 \AA$ PNIPAM brush in $\mathrm{H}_{2} \mathrm{O}$ (line to guide the eye) (b) Equilibrium QCM-D frequency, $\Delta \mathrm{f}_{3} / 3$, and dissipation, $\Delta \mathrm{D}$, response of a $209 \pm 10 \AA$ PNIPAM brush in $\mathrm{H}_{2} \mathrm{O}$. Curves are sigmoidal fits to the data. 


\section{Fitted Reflectivity Curves}

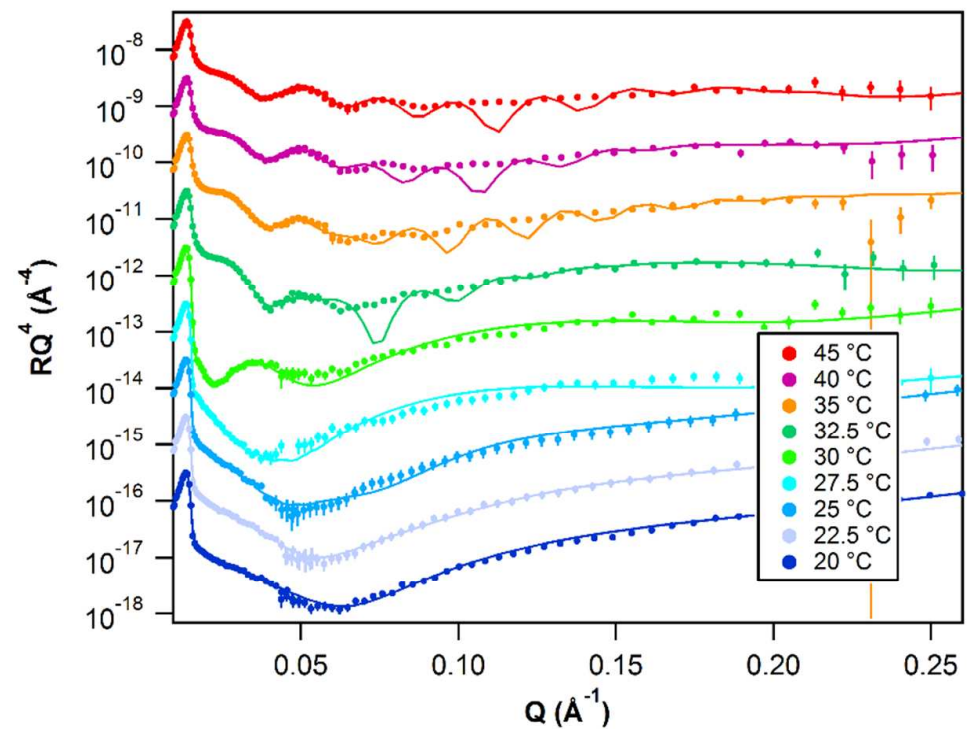

Figure S10. Measured reflectivity curves (filled circles) for equilibrium temperature measurements on a $191 \AA$ PNIPAM brush immersed in $100 \mathrm{mM}$ potassium acetate. The experiment was conducted from $45^{\circ} \mathrm{C}$ downwards. The solid lines are the fits to the experimental data. Data have been offset on the $R Q^{4}$ axis for clarity, with the data for $45^{\circ} \mathrm{C}$ plotted using actual recorded data

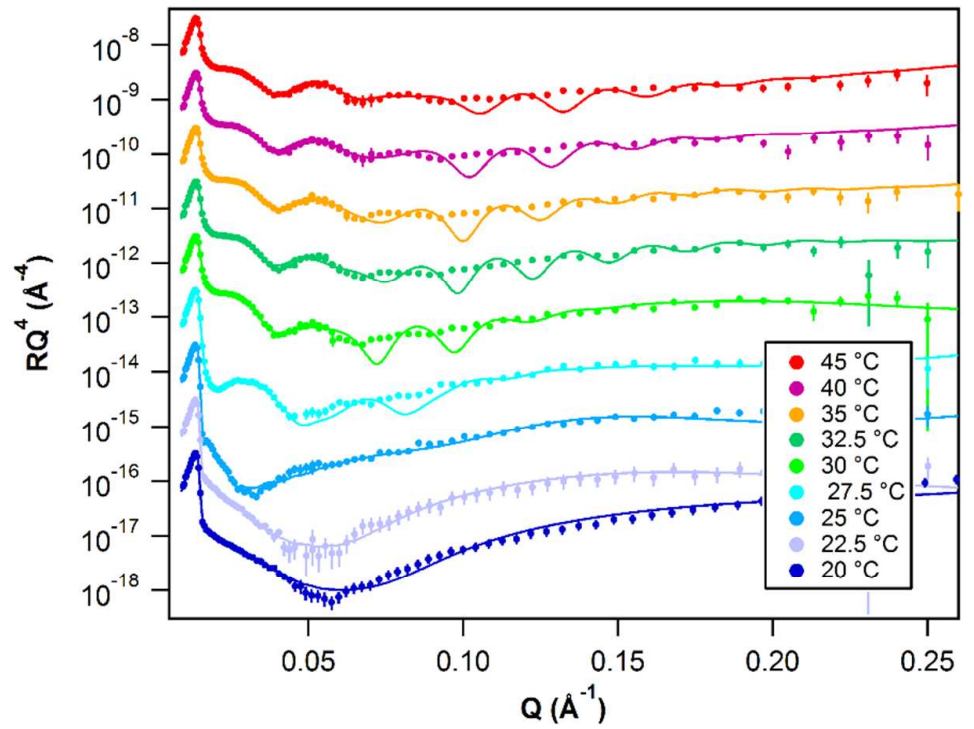

Figure S11. Measured reflectivity curves (filled circles) for equilibrium temperature measurements on a 191 Å PNIPAM brush immersed in $250 \mathrm{mM}$ potassium acetate. The experiment was conducted from $45^{\circ} \mathrm{C}$ downwards. The solid lines are the fits to the experimental data. Data have been offset on the $R Q^{4}$ axis for clarity, with the data for $45^{\circ} \mathrm{C}$ plotted using actual recorded data 


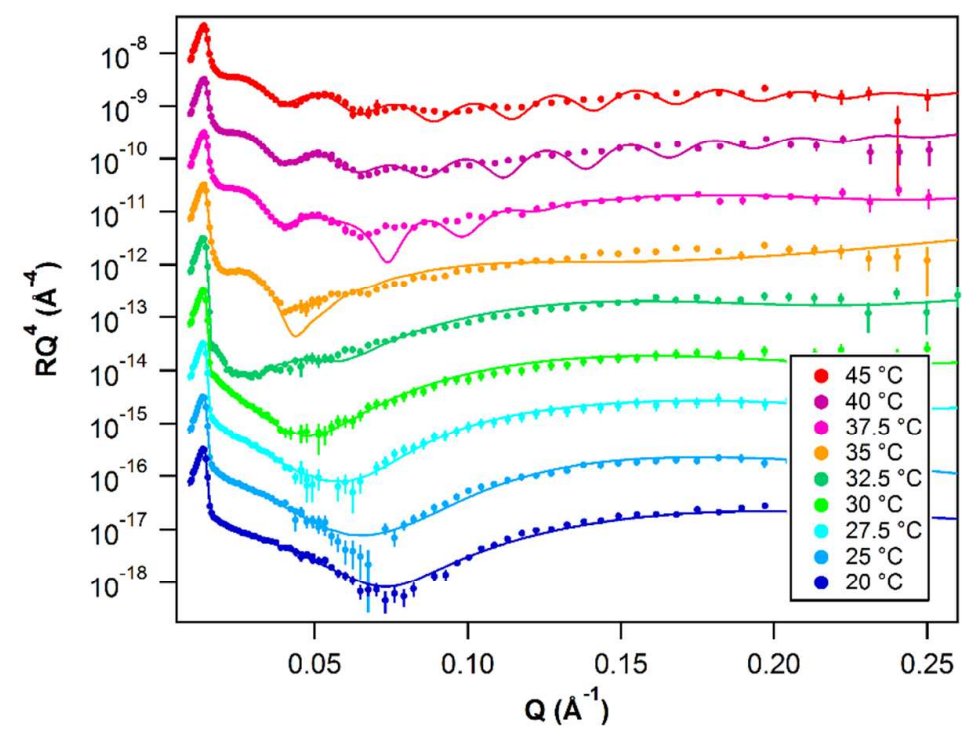

Figure S12. Measured reflectivity curves (filled circles) for equilibrium temperature measurements on a 191 A PNIPAM brush immersed in 100 mM potassium thiocyanate. The experiment was conducted from $45^{\circ} \mathrm{C}$ downwards. The solid lines are the fits to the experimental data. Data have been offset on the $R Q^{4}$ axis for clarity, with the data for $45^{\circ} \mathrm{C}$ plotted using actual recorded data

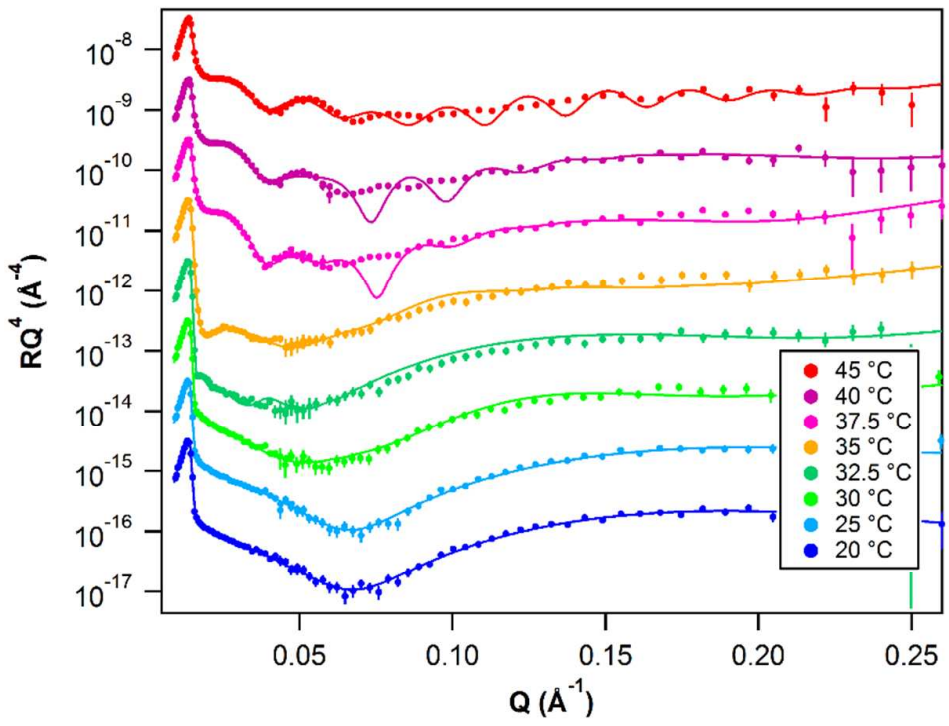

Figure S13. Measured reflectivity curves (filled circles) for equilibrium temperature measurements on a 191 Å PNIPAM brush immersed in 250 mM potassium thiocyanate. The experiment was conducted from $45^{\circ} \mathrm{C}$ downwards. The solid lines are the fits to the experimental data. Data have been offset on the $R Q^{4}$ axis for clarity, with the data for $45^{\circ} \mathrm{C}$ plotted using actual recorded data 


\section{Alternate representation of average brush thickness data}

Discussion surrounding Figure 5 states that there is a more gradual transition between the collapsed and swollen states in the presence of thiocyanate. To demonstrate this, the data in Figure 5 have been replotted in Figure S14 with the temperature axis offset relative to the discontinuity temperature. We define this temperature as the lowest measured temperature at which the brush is fully collapsed ( $245 \AA$ ) . Error bars on the plot represent two standard deviations for fits of similar $\chi^{2}$ values. These uncertainties are small for the fully collapsed $( \pm 10 \AA)$ and fully swollen states $( \pm 20 \AA)$, with slightly higher uncertainty at intermediate temperatures $( \pm 30 \AA)$. It is clear in Figure S14 that the brush thickness is systematically lower for a given temperature below the discontinuity temperature with increasing concentration of thiocyanate. The reduction in thickness is particularly evident for the $250 \mathrm{mM}$ data with the majority of data points below the discontinuity temperature distinct from the $\mathrm{D}_{2} \mathrm{O}$ and acetate conditions and data at -5 and $-10 \Delta^{\circ} \mathrm{C}$ is distinct from $100 \mathrm{mM}$ thiocyanate. The increase in brush thickness at $-2.5 \Delta^{\circ} \mathrm{C}$ below the point of discontinuity is less in the presence of thiocyanate; by an amount beyond the margin of error. Therefore the conclusion in the main manuscript is sound and the presence of ions does not merely move the LCST, but influences the brush nanostructure in the region in the vicinity of the LCST.

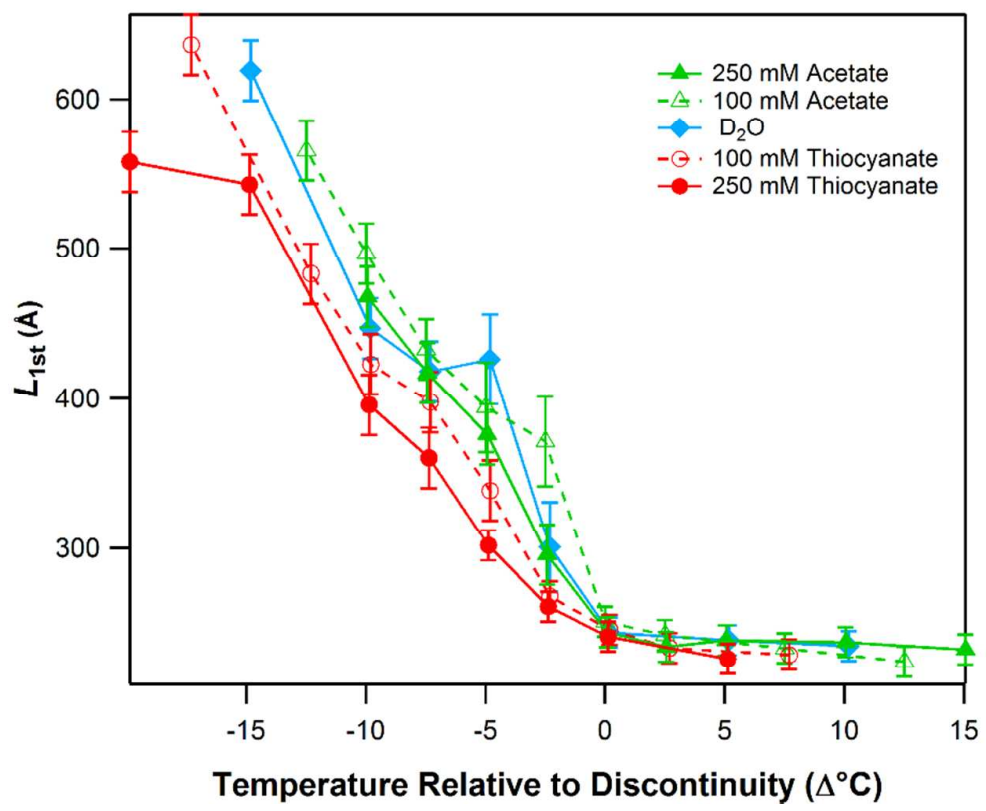

Figure S14. Average overall brush thickness determined by twice the first moment of the volume fraction profiles as a function of temperature relative to the discontinuity point (i.e. the lowest temperature at which the brush is fully collapsed). 


\section{Dense interior region parameterization}

The approach for parameterizing the fraction of polymer in the dense interior region is summarized in Figure $\mathrm{S} 15$ using the profile at $32.5^{\circ} \mathrm{C}$ in $\mathrm{D}_{2} \mathrm{O}$. The extent of the dense interior region was defined as the first minimum in the differentiated volume fraction profile for perpendicular distances greater than the initial spike (close to the substrate) in polymer density (see Main Article). Choice of the first minimum is shown in the inset of Figure S15. This point corresponds to the point of maximum negative slope in the transition between the dense interior and the swollen tail. If there is no significant minimum, the extent of the initial spike was taken instead and corresponds to the minimum near the substrate. The fraction of polymer in the interior region was calculated by dividing the integrated area in the dense interior region (shaded) by the total area under the volume fraction profile curve. The fraction of polymer in the dense interior region calculated in this manner is independent of solvent content. By this definition the fraction of total polymer in the dense inner region must equal 1 when the polymer brush is fully collapsed. This approach slightly underestimates the amount of polymer in the dense, interior region. However, this is expected to have minimal impact on the primary aim of determining a value for the LCST or transition temperature. Approaches based on the second differential were attempted but could not be interpreted objectively.

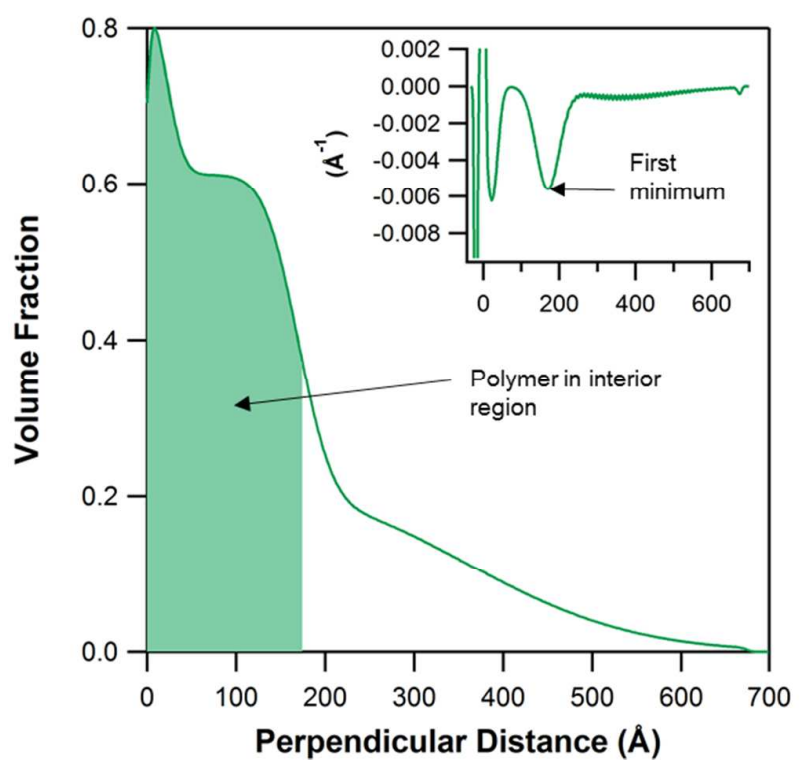

Figure S15 Example of determination of the amount of polymer in interior region. Shaded region indicates polymer associated with interior region while the inset shows the first differential of the volume fraction profile 


\section{References}

1. Abbott, S. B.; de Vos, W. M.; Mears, L. L.; Cattoz, B.; Skoda, M. W.; Barker, R.; Richardson, R. M.; Prescott, S. W. Is Osmotic Pressure Relevant in the Mechanical Confinement of a Polymer Brush? Macromolecules 2015, 48, 2224-2234.

2. Sanjuan, S.; Tran, Y. Stimuli-Responsive Interfaces Using Random Polyampholyte Brushes. Macromolecules 2008, 41, 8721-8728.

3. Sudre, G.; Hourdet, D.; Creton, C.; Cousin, F.; Tran, Y. pH-Responsive Swelling of Poly(acrylic acid) Brushes Synthesized by the Grafting Onto Route. Macromol. Chem. Phys. 2013, 214, 28822890.

4. Tomlinson, M. R.; Cousin, F.; Geoghegan, M. Creation of Dense Polymer Brush Layers by the Controlled Deposition of an Amphiphilic Responsive Comb Polymer. Polymer 2009, 50, 4829-4836.

5. Elliott, L. C.; Jing, B.; Akgun, B.; Zhu, Y.; Bohn, P. W.; Fullerton-Shirey, S. K. Loading and Distribution of a Model Small Molecule Drug in Poly(N-isopropylacrylamide) Brushes: A Neutron Reflectometry and AFM Study. Langmuir 2013, 29, 3259-3268.

6. Gao, X.; Kucerka, N.; Nieh, M.-P.; Katsaras, J.; Zhu, S.; Brash, J. L.; Sheardown, H. Chain Conformation of a New Class of PEG-Based Thermoresponsive Polymer Brushes Grafted on Silicon as Determined by Neutron Reflectometry. Langmuir 2009, 25, 10271-10278.

7. Geoghegan, M.; Ruiz-Pérez, L.; Dang, C. C.; Parnell, A. J.; Martin, S. J.; Howse, J. R.; Jones, R. A.; Golestanian, R.; Topham, P. D.; Crook, C. J. The pH-induced Swelling and Collapse of a Polybase Brush Synthesized by Atom Transfer Radical Polymerization. Soft Matter 2006, 2, 1076-1080.

8. Moglianetti, M.; Webster, J. R.; Edmondson, S.; Armes, S. P.; Titmuss, S. Neutron Reflectivity Study of the Structure of $\mathrm{pH}$-Responsive Polymer Brushes Grown from a Macroinitiator at the Sapphire-Water Interface. Langmuir 2010, 26, 12684-12689.

9. Topham, P. D.; Glidle, A.; Toolan, D. T.; Weir, M. P.; Skoda, M. W.; Barker, R.; Howse, J. R. The Relationship between Charge Density and Polyelectrolyte Brush Profile Using Simultaneous Neutron Reflectivity and In Situ Attenuated Total Internal Reflection FTIR. Langmuir 2013, 29, 60686076.

10. Jia, H.; Wildes, A.; Titmuss, S. Structure of pH-Responsive Polymer Brushes Grown at the Gold-Water Interface: Dependence on Grafting Density and Temperature. Macromolecules 2011, 45, 305-312.

11. Yim, H.; Kent, M.; Mendez, S.; Balamurugan, S.; Balamurugan, S.; Lopez, G.; Satija, S. Temperature-Dependent Conformational Change of PNIPAM Grafted Chains at High Surface Density in Water. Macromolecules 2004, 37, 1994-1997.

12. Yim, H.; Kent, M.; Mendez, S.; Lopez, G.; Satija, S.; Seo, Y. Effects of Grafting Density and Molecular Weight on the Temperature-Dependent Conformational Change of Poly $(N$ isopropylacrylamide) Grafted Chains in Water. Macromolecules 2006, 39, 3420-3426.

13. Yim, H.; Kent, M.; Satija, S.; Mendez, S.; Balamurugan, S.; Balamurugan, S.; Lopez, G. Evidence for Vertical Phase Separation in Densely Grafted, High-Molecular-Weight Poly( $N$ isopropylacrylamide) Brushes in Water. Phys. Rev. E 2005, 72, 051801.

14. Kobayashi, M.; Mitamura, K.; Terada, M.; Yamada, N. L.; Takahara, A. Characterization of Swollen States of Polyelectrolyte Brushes in Salt Solution by Neutron Reflectivity. J. Phys.: Conf. Ser. 2011, 272, 012019.

15. Kobayashi, M.; Terayama, Y.; Hino, M.; Ishihara, K.; Takahara, A. Characterization of Swollen Structure of High-Density Polyelectrolyte Brushes in Salt Solution by Neutron Reflectivity. J. Phys.: Conf. Ser. 2009, 184, 012010.

16. Karim, A.; Satija, S. K.; Douglas, J. F.; Ankner, J. F.; Fetters, L. J. Neutron Reflectivity Study of the Density Profile of a Model End-Grafted Polymer Brush: Influence of Solvent Quality. Phys. Rev. Lett. 1994, 73, 3407-3410.

17. Dunlop, I. E.; Thomas, R. K.; Titmus, S.; Osborne, V.; Edmondson, S.; Huck, W. T.; Klein, J. Structure and Collapse of a Surface-Grown Strong Polyelectrolyte Brush on Sapphire. Langmuir 2012, 28, 3187-3193. 
18. Zhang, J.; Nylander, T.; Campbell, R. A.; Rennie, A. R.; Zauscher, S.; Linse, P. Novel Evaluation Method of Neutron Reflectivity Data Applied to Stimulus-Responsive Polymer Brushes. Soft Matter 2008, 4, 500-509.

19. Halperin, A.; Kroger, M. Collapse of Thermoresponsive Brushes and the Tuning of Protein Adsorption. Macromolecules 2011, 44, 6986-7005. 